\title{
Hybrid Drilling: Advanced Approach
}

\author{
Kunal Kadam, Paresh Pawar, Pratik Katkade, Jayesh Kasar, Nikhil Joshi, Aditya Bulbule \\ Dr. Vishwanath Karad MIT World Peace University,
}

Pune

\begin{abstract}
Drilling is a process which basically establishes communication between surface and reservoir. For drilling processes like for vertical drilling or for horizontal drilling we use different types of drilling rigs which are basically equipped with power systems, mud circulation systems and all.

The industry is going to transition into efficient technologies and digitalization written all over it. As a part of digital transformation the industry is shifting from traditional drilling method to digitalization or digital twin.so we have elaborated in this paper how this can be useful in early detection of anomalies and increase process safety while drilling.

In normal drilling we use diesel powered engines but in many situation like in offshore conditions, remote places they are not efficient or in some situations they fail to deliver good result again some replacement like Spark Ignited (SI) Dedicated Engine, With dual-fuel engines, at low loads, the amount of diesel being displaced by natural gas is very low also sometimes cause higher emissions.so in this paper we have discussed about comparison different engines for different conditions.

Operators in the current oil and gas industry want to optimize their performance so in this paper we have discussed the use of hybrid drilling bit can deliver reduction in drilling time and enhance ROP by $65 \%$ with $24 \%$ reduction in stick/slip conditions.

Downhole measurement while drilling is challenge ,many sensor technologies fail to deliver good results, in this paper we compared some of downhole measurement technologies available and we get to know that Wireless Activated Drilling Microchip for Wellbore Temperature Measurement shown impressive results they can useful even in temperature $\geq 250^{\circ} \mathrm{C}$ and pressure $\geq 15 \mathrm{~K}$ psig.so overall using these replacements for drilling can enhance performance, increase process safety and gives optimized results in various situation like in HPHT condition or remote location or for exploratory type of wells.
\end{abstract}

\section{INTRODUCTION}

The concept of the overall drilling process is relatively simple. There is a potential reservoir located deep beneath the earth's surface. In order to gain access and extract oil or gas, a hole must be drilled through the various rocks, materials and layers to reach it.

- Before drilling, measurements are made to show where to drill.

- The material, the size of the hole and how deep to drill will determine the proper type of drill bit.

- It will also determine what type of Engine and Rig would be required in order to drill efficiently.

\section{The Following Paper discusses in depth about the new generation advancements in the drilling industry's overall components}

- The Concept of Digital Twin in Drilling.

- Types of Rig Engines \& their location Specific Effectiveness.

- Hybrid Drill Bit.

- New generation Microchip sensors in HPHT Wells.

\section{Digital Twin in Drilling}

Digital Twin is a digital replica of various physical systems and processes. It collects appropriate information from the sensors and makes it accessible to different manufacturing sections. It detects the issue before it has actually occurred. It helps in getting maximum out of a well, it is more useful in predicting results of complicated wells.

Digital Twin Drilling is a digital representation of real drilling well and is useful during training and real time operation. Functionality of digital twin drilling is based on advanced hydraulics and mechanical models, by combining real time data received during well during operation and operation and compared with calculated hydraulic and mechanical models it provides early detection anomalies and offers early diagnostic alarms that help avoid problems before they become serious. It improves efficiency, productivity, helps change parameters for optimal drilling, and detects problems in prior.

\section{Types of Rig Engines \& their location Specific Effectiveness}

Most modern oil rigs use internal combustion engines as their main power plants. Diesel oil is the principal fuel used, largely because of its availability \& partly because of its high calorific value which provides high power deliverability whenever required. However some rigs have advanced into use of Natural gas as main power driving source and reduced cost significantly. 


\section{Things taken into consideration while selecting an engine for the rig}

1. Things that must be considered when selecting the optimal engine type for your operation is the quality of natural gas used as fuel, the speed at which the operation needs to be completed, and power needed to fulfill load demands.

2. There are different ways in which natural gas can be used for power within the oil and gas industry. Some of these power sources include the spark-ignited (SI) dedicated engine, dual-fuel engine, hybrid power, and gas turbines.

3. Last important factor is the availability of fuel at remote locations.

\section{Hybrid Drill Bit}

The process of cutting the rock and flushing drill cuttings results in a drill hole. The Drill Bit is the heart of the drill string \& therefore its proper selection \& use cannot be overemphasized. The drill bit crushed Rock under combined action of weight on bit \& Rotary Speed. The chippings are flushed away by the circulation fluid, to allow the bit to attack a new surface of rock.

\section{Following are the Types of Drill Bits used in the oil field Industry}

1. Roller cone Bit

2. PDC Bit

3. Diamond Bit

4. Hybrid Drill Bit

Recently there is advancement into Drill bit \& New generation Hybrid Drill Bit is up into the picture. This paper mainly focuses on Hybrid Drill bit and its recursive use in modern day.

\section{This study illustrates the following relationships:}

1.Compares hybrid drill bit to PDC drill bit performance.

2.Displays advancements in durability of cutting structure.

3.Displays enhanced erosion resistance of hybrid drill bit.

4. Illustrates an application study with continuous process improvement.

\section{New generation Microchip sensors in HPHT Wells}

Surface and down-hole sensors have been deployed to measure related physical phenomena that can be generally associated with the actual environment. Some direct measurements have been made after drilling using sensors suspended on a wire line, and this evolved into near real-time measurements using Measurement While Drilling (MWD) and Logging While Drilling (LWD) equipment that use low bandwidth pulse telemetry communications. With the advent of high speed wired drill pipe, new sensors are needed to take advantage of the improved telemetry capabilities to produce true real-time measurements.

Three types of measurement are needed in this environment: temperature, pressure, and differential pressure. The HPHT sensors, along with accurate flow measurement, could provide the basis for accurate revenue and royal allocation, as well as improved reservoir management in highly challenging HPHT wells. The paper Discusses in depth details about the Wireless activated Drilling Microchip for wellbore temperature Measurement $\&$ the advancements of Battery in it over the years, the protective casing over the Battery \& HPHT working Conditions.

\section{Digital Twin In drilling}

The industry is going to transition into efficient technologies and digitalization written all over it. As a part of digital transformation the industry is shifting from traditional drilling method to digitalization or digital twin.

The concept of digital twin was introduced by Dr. Michael Grieves at university of Michigan in 2002. Digital twin is digital copy of physical system. It is a more advanced and cost effective method. In drilling, use advanced down hole data and 
advanced down physical drilling systems based on thermo-hydraulic and mechanical models during life time of well construction.

\section{Advantages of Using Digital Twin in Drilling}

1. Provides several benefits to operations and improves drilling performance

2. It can realize early detection of anomalies

3. It can help to reduce non-productive time and increase safety

4. It reduces time and gives better accuracy and is cost effective

\section{Introduction}

Digital Twin is a digital replica of various physical systems and processes. It collects appropriate information from the sensors and makes it accessible to different manufacturing sections. It detects the issue before it has actually occurred. It helps in getting maximum out of a well, it is more useful in predicting results of complicated wells.

Digital Twin Drilling is a digital representation of real drilling well and is useful during training and real time operation. Functionality of digital twin drilling is based on advanced hydraulics and mechanical models, by combining real time data received during well during operation and operation and compared with calculated hydraulic and mechanical models it provides early detection anomalies and offers early diagnostic alarm that help avoid problems before they become serious. (Oke K. 2018; Odegaard S I. 2018; Gholami Mayani et al. 2018) It improves efficiency, productivity, help change parameter for optimal drilling, and detects problems in prior

\section{Digital Twin A Digital Twin in drilling can consist of the following elements}

1. The physical well.

2. The digital footprint of the physical well

3. Advanced dynamic mathematical models of most important physical effects during drilling. These are driven by RT data from the drilling process

4. Real Time analytics of all data available (measured and modelled) can provide supervision and diagnostics of the drilling

5. 2D and 3D representations of the available process data (rommetveit2019)

\section{Deployment and use in DMC}

A science and technology center (STC) has been established to enhance oil production throughout deployment of new technology in operation. As a part of STC a drilling management center was established to increase drilling performance and reduce NPT. The digital receives data in real time, with WITSML that transmits well site data from rig to different stakeholders in the oil and gas industry. Results are probably displayed on video wall

\section{Modeling basis used in Digital Twin development}

The basis of the Digital Twin system is developed from first principles of physics. The Digital Twin uses all available real-time drilling data; both surface and downhole. These are linked to and combined with real time modelling to supervise and optimize the drilling process. The RT data as well as configuration and other relevant data are used to visualize the wellbore and the drilling process status in $3 \mathrm{D}$ in real-time.

\section{The Digital Twin is composed of}

An advanced and fast integrated drilling simulator, integrating transient hydraulic, thermal and mechanical models. The integrated drilling simulator model the different drilling sub-processes dynamically. The interaction between the subprocesses are also modelled in real-time. This simulator is used to perform forward-looking automatically and can be used for re-planning on the-fly (what-if) as well.

- Automatic corrections and quality check of the drilling data; so that these are suitable for processing by computer models.

- Algorithms monitoring of the drilling process in real-time by means of a combination of time based drilling data and real-time modelling data results. 
- Algorithms for diagnosis of the drilling state.

- A 3D visualization (Virtual Wellbore), with dynamic visualization of the downhole process.

- Data flow and computer infrastructure

\section{Summary of Digital twin Application In A Real Time Monitoring For Well In South China Sea}

\section{Warning of an upcoming event was given RT monitoring system}

1. It contributed significantly to the reduction of non productive time by $60 \%$ in this well, it is also safer and cheaper operation in general was promoted

2. A kick development was diagnosed early and warning communication to rig

3. A loss scenario was diagnosed early, and warning communicated to rig

4. Hydraulic calculation gave reasonable suggestions for mud density to avoid leakage and inflow and good simulation reduced risk

5. No accident happen in tripping in casing, circulating or cementing with close monitoring with digital twin

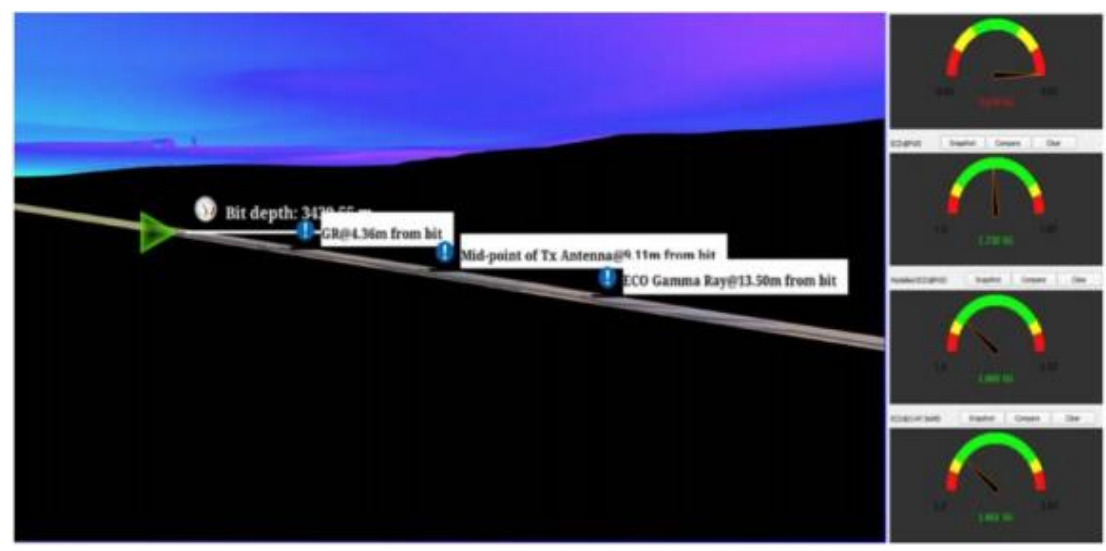

Fig 1. Dynamic 3D View of the wellbore with ECD gauges and information messages

\section{Rig Engines}

\section{Focusing on fuel availability at remote locations -}

\section{Available types of engines for selection}

\section{Spark Ignited (SI) Dedicated Engine}

The SI engine is a form of an internal combustion engine that uses a spark plug to ignite the air/fuel mixture within the combustion chamber of the engine. The energy produced within the combustion chamber of the engine then in turn directly applies force to a component on the engine, transferring chemically produced energy into mechanical. SI dedicated engines can completely be powered off natural gas and can offer maximum fuel savings for operators. However, these engines tend to be heavier and larger in size compared to diesel engines and are not good for instantaneous high transient loads due to slow flame speed in the combustion chamber and a greater potential for engine knocking. Essentially, it takes a while for these engines to ramp up into high gear. A white paper composed by Environmentally Friendly Systems (LaFleur, H.H.C. 2013) suggests that hydrogen can be added to enrich the fuel and improve combustion characteristics. These engines are capable of using a wide range of fuel from LNG to propane, they produce low GHG emissions and are mobile. Part of the challenge with using wellhead associated gas for power is the high BTU content and natural gas liquids that are contained within associated gas. There are some engine types available that can use high BTU wellhead gas, but in general these types of engines you will face a longer transient response time. The higher the BTU content of the natural gas used the slower the engine will take to ramp up to the higher engine load swings. Companies are now in the process of designing engines that can run on variable natural gas BTU content, but this cannot be achieved without the sacrifice of transient load time. However, one thing to consider is when using wellhead gas with higher BTU content there will be degradation in engine parts decreasing the component life of the overall system and thereby leading to higher maintenance. Caterpillar and GE both have engine types and parts available with the capacity to run off higher BTU quality wellhead gas. However, necessary retrofitting for use in these particular applications is time-consuming and requires additional 
capital (Juergens 2013). Also, a control system enabling the engine to manage the variable quality of wellhead gas leads to additional costs as well (Jacobs 2014).

\section{Dual Fuel Engine}

With the capacity to run off both natural gas (LNG or CNG) and diesel fuel, dual-fuel engines are used most in the industry today. It is possible either to buy a new dual-fuel engine or get a conversion kit to retrofit a diesel engine. A study was done by Mustafi et al. (2013) which discussed differences in the performance and pollutant emissions when using natural gas with dual-fuel engines compared to the use of diesel-fueled engines. The testing of these engines using different types of fuel has shown that when using natural gas there is a significant reduction in $\mathrm{CO} 2, \mathrm{NOx}$, unburned hydrocarbon, and particulate matter emissions. Results also show low brake specific fuel consumption versus using diesel fuel. The brake specific fuel consumption is the ratio of fuel used to the amount of power produced by the engine. When this ratio is low, the engine will use less natural gas compared to diesel for the amount of power produced. According to Caterpillar, they have developed a dynamic gas blending dual-fuel technology that can substitute up to $70 \%$ of diesel with natural gas while the engine is functioning at a 30 to $80 \%$ load. This type of engine can use natural gas with the lower heating value BTU content ranging between 8001250 This technology also can dynamically adjust while continuing to substitute diesel with natural gas as fuel quality changes (Ternes 2013).

When using these engines all-natural gas liquids must be removed from the fuel. Small amounts of water in the fuel are okay but it must contain no hydrogen sulfide. These engines can be fueled using natural gas with the methane number between 30 to 100 , however, the higher the methane number the lower the amount of natural gas that can be substituted for diesel (Gore 2013).

The transients in this type of engine are handled by injecting more diesel than natural gas. One of the challenges most drillers find when running multiple engines at low loads is that the amount of diesel being displaced by natural gas substitution becomes uneconomical. It takes more diesel to power these engines at lower speeds than natural gas, leading to not much of a reduction in engine emissions (Juergens 2013; LaFleur, R.H.C. 2013). For dual-fuel engines, there is a "sweet spot operating zone where maximum diesel fuel displacement occurs. When operating dual-fuel engines above or below the "sweet spot" power range, diesel displacement rates decrease. Operating outside of the sweet spot ranges too frequently may lead to the uneconomical use of these engines.

\section{Gas Turbines -}

Gas turbines are another form of an internal combustion engine. They provide significant benefits due to versatility, high power to rate ratio, and ability to be powered by several forms of combustible fuels (including those that contain $\mathrm{CO}$, and $\mathrm{H}, \mathrm{S})(\mathrm{LaFleur}$, R.H.C. 2013). However, this form of engine is best used for applications where constant high power operations are needed. These engines do not take transient loads very well. They are typically designed to work optimally for a certain operating range. As power output decreases so does the engine's efficiency. Turbines are typically designed to operate peak loads greater than $50 \%$. These loads can be sustained for 2-3 years, but 3-4 years after use these maximum loads drop off to 20-30\% less than what they are rated for, and power capacity decreases (Juergens 2013).

\section{Hybrid Power -}

Hybrid power is a new technology that has been developed where an ultracapacitor is used in conjunction with an engine to supply power. One type is called the FlexGen ultracapacitor system. There are different battery storage capacities available for use which can be customized for the type of job needing to be done and the amount of power needing to be supplied. Hybrid power is scalable and modular, making it feasible for use in remote areas. Since the market for these systems hasn't been established yet in the oil and gas industry, this option may be more expensive. Pricing for this option majorly depends on the battery chemistry used, the number of battery cycles needed, and the duration required to meet high energy demands. The battery chemistry determines performance quality, lifespan an operator would like to get out of this type of system, and the deep battery cycles. Lifespan on an ultracapacitor could range anywhere between 5-12 years. The maintenance required for this type of system is roughly 2 hours of downtime on an annual basis. Since this system allows engines to operate in its most efficient capacity, it has the potential to reduce fuel needs up to $15 \%$ (Juergens 2013).

For SI engines, when the rig is tripping pipe and the load changes the ultracapacitor will harness excess power supplied from the generators when there is not a huge load demand. When those high load demands are needed, the ultracapacitor can sustain 2030 seconds of a high amount of instantaneous power that will supplement the other power generators in use until they can ramp up and meet those load demands. Knowing that dedicated natural gas engines have a slower transient response time compared to diesel engines, this option may be the solution. What is unique about this system is it offers the flexibility to use a wider range of natural gas qualities to fuel SI engines providing all the transient capabilities needed for the rig (Juergens 2013),

\section{Outcomes of Comparison}


1. SI engines are powered by natural gas but are heavier than diesel engines and not good at load time, that's why they are not useful at remote locations.

2. Gas Turbine engines could be a good option for remote locations but the main problem is with the fuel required and degradation in efficiency after 3-4 year about 30-40\%.

3. With dual-fuel engines, at low loads, the amount of diesel being displaced by natural gas is very low, sometimes making them uneconomical, causing higher emissions, and incurring more maintenance.

4. Hybrid systems can offer an advantage to offset power loads for 1-2 generators into that higher operating range so that the engine can become more economically efficient, reducing maintenance, and lowering emissions.

5. Remote Locations Hybrid System can be used according to study.

\section{Hybrid Drill Bit}

Hybrid bits combine the crushing and gouging action of roller cones with the shearing action of PDC cutting elements (See Fig. 2). The roller cone elements pre-fracture the formation, weakening the rock to make it easier to shear. The fixed cutter elements can then more readily remove the formation between the indentations made by the rolling cones. The combined cutting action results in much higher ROP than is achievable with roller cone bits, and with improved stability compared to conventional fix ed cutter PDC bits.

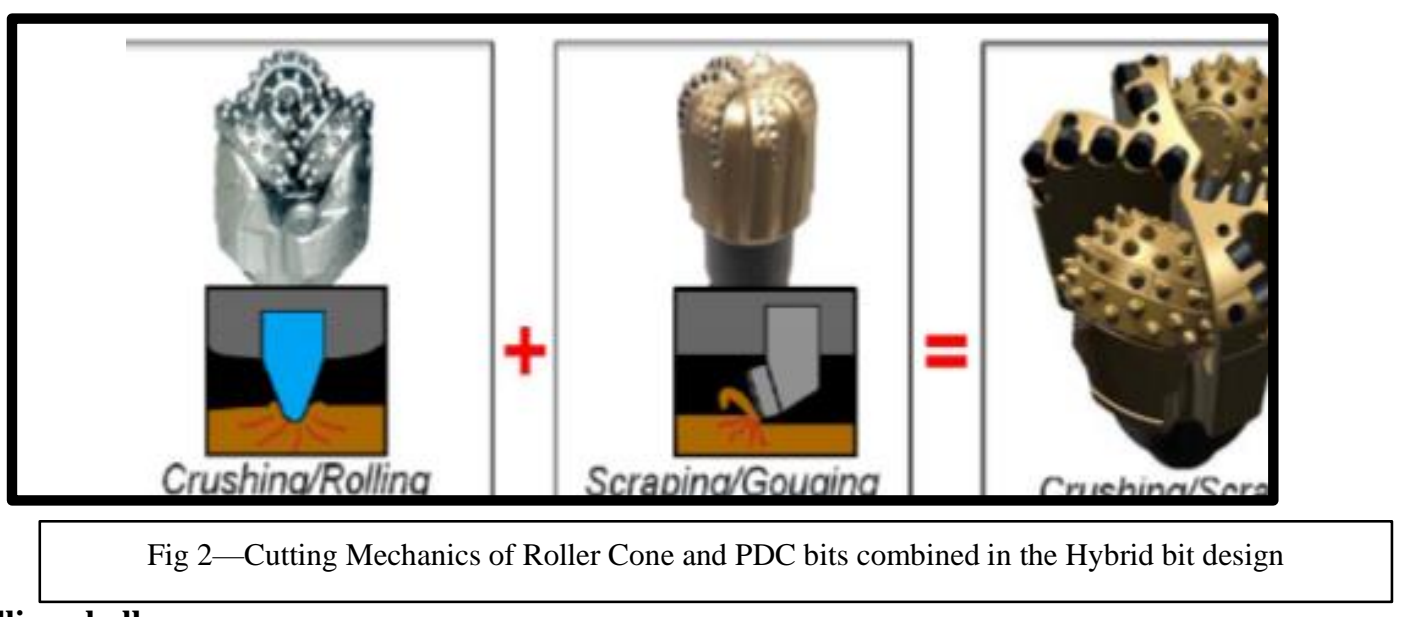

\section{Drilling challenges}

According to previous studies Conventional TCI bits on rotary or motor assembly drill are relatively efficient in the top part of the section formation. When reaching the lower part of the section, TCI bits show a significant drop in average ROP. On the other hand, PDC bits are also exposed to high impact in the transition zone while shearing the rocks, making them not cost effective. Torque fluctuation and torsional vibration are commonly observed while drilling with PDC even with vibration mitigation techniques. Torsional vibration and premature damage in cutting structure directly impact the performance and the overall average section penetration rate

offset data analysis shows inconsistency in performance and ability to reach the section TD when using TCI bits. This can occur because of different reasons such as slow ROP, reaching maximum drilling hours, bit dull condition, etc. from the previous study Pie chart below shows the collected data of 863 runs in the some field and the percentage of TCI that pulled out prematurely verses reached section TD 


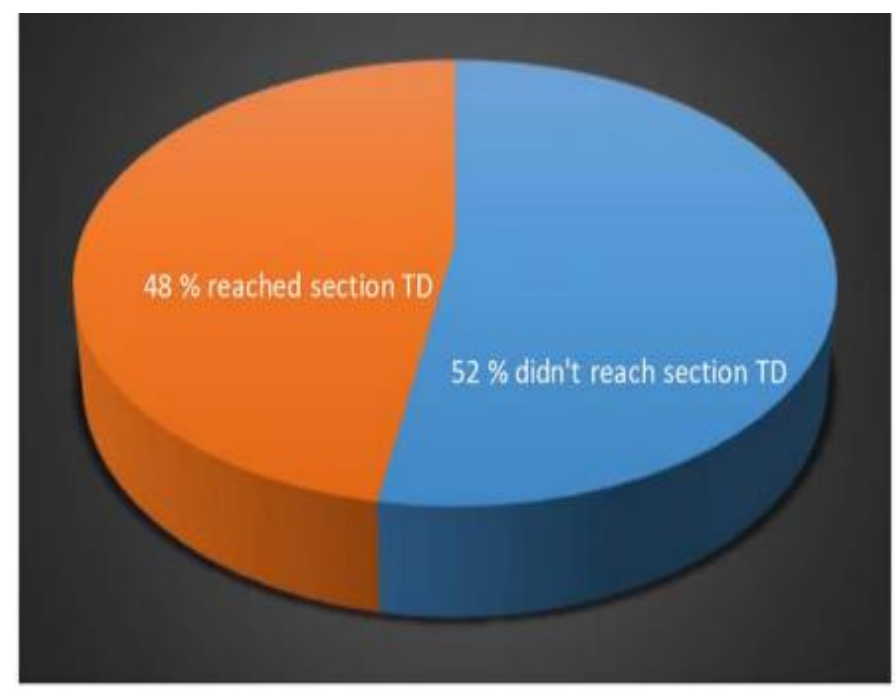

Fig 3. Percentage of TCI completed section

\section{Implementation of Hybrid Bit Technology}

With the performance barriers identified, the technology enablers could be defined to mitigate them and improve drilling performance in the interval. After using this technology according to study they Observed good ROP rates and economical benefits give rise further study and evolution scope.Early hybrid bit technology, bit design consists of two roller cones and four blades. The bit uses a sharp and dense roller cone insert design for high efficiency drilling. Later, the carbide inserts serving as secondary protection were removed to increase the aggressiveness of the cutting structure. The changes did result in an improvement in average overall ROP of $13 \%$, from $54.8 \mathrm{~m} / \mathrm{hr}$ to $62.1 \mathrm{~m} / \mathrm{hr}$. In the last iteration face cutters improved with more impact resistant grade.

\section{Results}

\section{Dull Grade Review}

- More ability of combined cutting structure to drill significantly further with sustaining some erosion to the body.

- Hardfacing on a steel body frame has displayed the ability to resist erosion better than matrix framed PDC bits.

\section{Improvements in Drilling Dynamics}

- The hybrid had drilled the carbonate with a $24 \%$ reduction in stick/slip

- $65 \%$ improvement in ROP compared to the conventional PDC bit.

\section{Downhole sensor technology}

\section{Raman Distributed Temperature Sensing System}

\section{Brief}

A Raman scanner works in principle by sending a brief laser light pulse down an optical fiber. At all points along the fiber, minute portions of this light are scattered and reflected due to various mechanisms, one of which is the Raman effect. The Raman effect will cause the reflected light to have a different wavelength than the incident light. By measuring the wavelength of the reflected light, and the time at which it was reflected, the temperature at each location along the fiber can be measured with high precision. An alternative technique (although with more complex physics.

\section{Drawbacks}

A large part of downhole fiber-optic sensors do not survive installation, and a large part are also destroyed soon after installation (experience data from some operators). After one year of operation, $50 \%$ or so of fiber-optic downhole sensors may be nonoperable 


\section{HPHT Sensor}

\section{Brief}

Subsea multiphase flowmeters are increasingly being used as production has increased in the Gulf of Mexico as well as other locations around the world. Most of the currently installed subsea multiphase and wet-gas flow meters are limited to measurement of production fluids at a maximum temperature of $125^{\circ} \mathrm{C}$ and operating pressures of 10,000 psig. Improvements are required in the design of the mechanical components of the meters to allow qualification for operational pressures up to $15,000 \mathrm{psig}$. For operation at that pressure, the flow meter must be tested at 22,500 psig. The temperature limitation is related to the sensors that measure the produced fluids. Ultra deep and long tie-back systems may require subsea HP/HT multiphase metering systems for well test and allocation measurement instead of using a test flow line. Three types of measurement are needed in this environment: temperature, pressure, and differential pressure. These HPHT sensors, along with accurate flow measurement, could provide the basis for accurate revenue and royal allocation, as well as improved reservoir management.

\section{Drawback}

Improvements to Deepwater Subsea Measurement with the realization that this sensor market is small and the needed HP/HT sensors might not be developed through a commercial-only approach. Thus, this project focused on qualifying and/or developing sensors for the HP/HT environment:

- Temperature (production fluids) $\geq 250^{\circ} \mathrm{C}$

- Pressure (production fluids) $>15 \mathrm{~K}$ psig

- Water depth $>3 \mathrm{~K}$ meters $(4.3 \mathrm{~K}$ psig)

\section{Wireless Activated Drilling Microchip for Wellbore Temperature Measurement(confirmed)}

During drilling operations, initialized microchips are dropped into the drill pipe while making pipe connections. The microchips travel downwards in the drill pipe and pass through the bit nozzle carried by the mudflow. Then microchips are pushed upwards in the annular section and are eventually recovered at the shale shaker. Distributed downhole parameters such as temperature and pressure measurements are recorded periodically in the memory of the microchip, which can be downloaded entirely after the recovery process. The lab test result shows the new generation microchip is able to work longer in lower power consumption under simulated extremely harsh conditions. By applying different lightweight protective material, microchip can adjust its own density close to the mud density to make it easier for flowing upward in the annular section. This way the microchip recovery rate can be increased in the field. The field test results show an excellent correlation between the measurements and the pump flow rate. The reliability and integrity of the 3rd generation microchip under harsh downhole conditions has been improved. Larger capacity battery has been used to provide sufficient power for the whole system when sampling downhole. Meanwhile, an innovative wireless initialization module has been applied in the 3rd generation microchip. This way the microchips can be initialized using wireless method instead of plugging jumper wires, which can be time-saving and user friendly in the field application. Another improvement is the microchip protective material. Multiple lightweight protective material has been selected for the protective shell. It not only provides microchip better protection against higher temperature, higher pressure under downhole conditions, but also lowers the microchip density close to the circulating fluid density, which can be an advantage while the circulating microchips flow upwards in the annulus section.

\section{Properties :}

Battery The 3rd generation battery has much high reliability at high temperature. The wider working temperature range of the new battery provides much better performance in the high temperature environment. The battery life was extended to more than 28 hours, with more than 6 hours under high temperature conditions.

Table 1. Comparison of batteries used in different generations

\begin{tabular}{|l|l|l|l|l|l|}
\hline Battery Type & Nominal capacity & $\begin{array}{l}\text { Max Discharge } \\
\text { current }\end{array}$ & Life cycle & Diameter & HT Reliability \\
\hline $\begin{array}{l}\text { Battery used in } \mathbf{1}^{\text {st }} \\
\text { generation }\end{array}$ & $1 \mathrm{mAh}$ & $0.10 \mathrm{~mA}$ & 100 & $4.8 \mathrm{~mm}$ & Low \\
\hline $\begin{array}{l}\text { Battery used in } \mathbf{2}^{\text {nd }} \\
\text { generation }\end{array}$ & $2 \mathrm{mAh}$ & $0.05 \mathrm{~mA}$ & 50 & $4.8 \mathrm{~mm}$ & Low \\
\hline $\begin{array}{l}\text { Battery used in } \mathbf{3}^{\text {rd }} \\
\text { generation }\end{array}$ & $3.4 \mathrm{mAh}$ & $.15 \mathrm{~mA}$ & 100 & $6.8 \mathrm{~mm}$ & High \\
\hline
\end{tabular}




\section{Protective material}

Different light weight epoxies have been selected for the new generation of microchip. The light weight epoxies not only have excellent mechanical strength and high glass transition temperature, but also have much lower density $(0.6 \mathrm{~g} / \mathrm{cm} 3 \mathrm{to} 0.9 \mathrm{~g} / \mathrm{cm} 3)$ compared to the original epoxy $(1.2 \mathrm{~g} / \mathrm{cm} 3)$. Therefore, by applying light weight epoxies, the density of the microchip can be adjusted to the desired value which is closed to the mud density

\section{Working in HPHT conditions}

In the battery development of the new generation microchip, a special coating is studied and applied to enhance the protection of battery against high temperature and high pressure. By applying this special coating, the risk of battery damage in the microchip is much lower under high pressure high temperature conditions. The microchips with the special battery coating lasted much longer than the microchips without coating. The working lives of the microchips with coating is almost twice as much as the working lives of the microchip without coating. This proves that the coating does provide a much better protection for the battery under HPHT conditions

\section{Outcome of Comparison}

1.Fibre Optic Sensors are not durable.

2.HPHT sensors can't handle Deepwater conditions ,limited range of operations.

3. Wireless Activated Drilling Microchip is able to work longer in lower power consumption under simulated extremely harsh conditions and can adjust its density according to mud density that's why it easily flows through the annular section.

\section{CONCLUSION}

After comparison and study of these 4 aspects of drilling on the basis of their use in different conditions and durability and performance and efficiency.

\section{The following conclusions can be obtained after comparative study of technologies of these aspects}

1. Digital twin technology gives Real Time analytics of all data available (measured and modelled) can provide supervision and diagnostics of the drilling with 2D and 3D representations of the available process data and increase drilling safety.

2. SI Engines and gas turbine engines failed in High load times and had more fuel requirements while Hybrid engines provide effective solution with high operating range and reduce maintenance and cost effective also.

3. A significant improvement in drilling performance can be achieved through the use of hybrid.mechanism delivered an improved in ROP and increased in run-length. Again high erosion resistance gives decrease in drilling cost.

4. In HPHT conditions Wireless Activated Drilling Microchip is able to work longer in lower power consumption with flexibility to adjust itself in drilling conditions.

5. These are some replacements that can provide us with a better drilling environment with good operation efficiency and enhanced performance with improved process safety.

\section{REFERENCES}

1. Blikra, H., Pia, G., Wessel, J. S., Svendsen, M., Rommetveit, R. and Ødegård, S. I.: "The Operational Benefit of Testing HPHT/MPD Procedures Using an Advanced Full-Scale Drilling Simulator"; SPE 167958 presented at the SPE/IADC Drilling Conference and Exhibition held in Fort Worth, Texas, USA, 4-6 March 2014. http://dx.doi: 10.2118/167958MS

2. Barr Aas, I., Skjerve, K., Haaland, L.E., Svendsen, M. and Rommetveit, R.; "Successful Use of Sophisticated Flow Modelling in the Planning and Operational Phase of Drilling, Liner Running and Cementing Operations: All in Managed Pressure Mode." SPE-181474-MS presented at the SPE Annual Technical Conference and Exhibition held in Dubai, UAE,26-28 September 2016.

3. Mayani, M. G., Svendsen M, Oedegaard S. I, Drilling Digital Twin Success Stories the Last 10 Years, SPE-191336-MS, Society of Petroleum Engineers, paper presented at SPE Norway One Day Seminar held in Bergen, Norway, 18 April 2018 ttp//dx doi:10.2118/191336-MS

4. Grieves M. Product Lifecycle Management: Driving the Next Generation of Lean Thinking, McGraw-Hill Education, 2006

5. Rommetveit, R., Bjorkevoll, K. S., Odegaard, S. I., Herbert, M. C., \& Halsey, G. W., Automatic Real-Time Drilling Supervision, Simulation, 3D Visualization, and Diagnosis on Ekofisk, Society of Petroleum Engineers. SPE-112533-MS, 2008 ttp://dx.doi:10.2118/112533-MS

6. Piascik R, Vickers J, Lowry D, Scotti S, Stewart J, Calomino A. Technology area 12: Materials, structures, mechanical systems, and manufacturing road map. NASA Office of Chief Technologist, 2010.

7. Maryam Gholami Mayani, eDrilling; Timur Baybolov, GazPromNeft-NTC; Rolv Rommetveit and Sven Inge Ødegaard, eDrilling; Vitaly Koryabkin and Sergey Lakhtionov, GazPromNeft-NTC," Optimizing Drilling Wells and Increasing the Operation Efficiency Using Digital Twin Technology", IADC/SPE International Drilling Conference and Exhibition This paper was prepared for presentation at the IADC/SPE International Drilling Conference and Exhibition held in Galveston, Texas, 3-5 March 2020

8. Ternes, S. 2013. "Drilling \& Production with Natural Gas”. In Powered by Natural Gas Workshop, ed. 12 SPE-173491-MS Ternes, S. San Antonio, TX: Caterpillar.

9. Lafleur, R.H.C. 2013. "Natural Gas Fuel for Drilling and Hydraulic Fracturing: The Basics of Natural Gas Power \& Fuel”. www.efdsystems.org Accessed $8 / 3 / 2014$.

10. Mustafi, N.N., Raine, R.R., and Verhelst, S. 2013. "Combustion and Emissions Characteristics of a Dual Fuel Engine Operated on Alternative Gaseous Fuels". Fuel 109(0): 669 -678. DOI: http://dx.doi.org/10.1016/j.fuel.2013.03.007 
11. Gore, J.A. 2013. "Dual Fuel Engines". In Powered by Natural Gas Workshop: 32. San Antonio, TX: Cummins.

12. Waleed Al-Baghli, Kuwait Oil Company; Atef Abdelhamid, Ali Alnemer, Baker Hughes, GE company," Hybrid Drill Bit Technology on Performance Motor Bottom Hole Assembly Yields Breakthrough Drilling Performance in Kuwait”, SPE/IATMI Asia Pacific Oil \& Gas Conference and Exhibition held in Bali, Indonesia, 29-31 October 2019. SPE-196481-MS.

13. Kim Bone, Baker Hughes, a GE company; Ben Bradley and Ibrahim Kale, Santos," Next-Generation Hybrid Drill Bit Produces Exceptional Drilling Dynamics and Time-Saving Improvements", presented att the Offshore Technology Conference held in Houston, Texas, USA, 6 - 9 May 2019. OTC29440-MS.

14. Pessier, R. and Damschen, M. 2010," Hybrid Bits Offer Distinct Advantages in Selected Roller-Cone and PDC- Bit Applications", Presented at the IADC/SPE Drilling Conference and Exhibition, New Orleans. SPE-128741 .

15. J. E. Hall, Letton-Hall ,"High-Pressure/High-Temperature Sensor Development and Qualification", Offshore Technology Conference This paper was prepared for presentation at the Offshore Technology Conference held in Houston, Texas, USA, 30 April-3 May 2012.

16. Zhaorui Shi, Yu Technologies, Inc. Tulsa, OK, USA; Bodong Li, Chinthaka Gooneratne, and Guodong David Zhan,"Wireless Activated Drilling Microchip for Wellbore Temperature Measurement”, Drilling technology Division, EXPEC Advanced Research Center, Saudi Aramco, Dhahran, Saudi Arabia Copyright 2020, International Petroleum Technology Conference This paper was prepared for presentation at the International Petroleum Technology Conference held in Dhahran, Saudi Arabia, 13 - 15 January 2020 